\title{
Coulisses
}

Revue de théâtre

19 | Hiver 1999

Varia

\section{Le Vampire dans la littérature et au théâtre}

Florent Montaclair - Presses du Centre UNESCO de Besançon, 1997

\section{Gilles Garbagnati}

\section{(2) OpenEdition}

\section{Journals}

Édition électronique

URL : https://journals.openedition.org/coulisses/5723

DOI : $10.4000 /$ coulisses. 5723

ISSN : 2546-9460

Éditeur

Presses universitaires de Franche-Comté

\section{Édition imprimée}

Date de publication : 1 janvier 1999

Pagination : 61-62

ISBN : 2-913322-09-3

ISSN : $1150-594 \mathrm{X}$

\section{Référence électronique}

Gilles Garbagnati, «Le Vampire dans la littérature et au théâtre », Coulisses [En ligne], 19| Hiver 1999, mis en ligne le 18 octobre 2019, consulté le 03 janvier 2022. URL : http://journals.openedition.org/ coulisses/5723; DOI : https://doi.org/10.4000/coulisses.5723

Ce document a été généré automatiquement le 3 janvier 2022.

Coulisses 


\section{Le Vampire dans la littérature et au théâtre}

Florent Montaclair - Presses du Centre UNESCO de Besançon, 1997

Gilles Garbagnati

1 Le vampire est une figure de l'imaginaire traité en littérature, au théâtre, au cinéma. Florent Montaclair se pose les questions suivantes :

- Pourquoi les créatures vampiriques apparaissent-elles au XVII ${ }^{e}$ siècle dans des récits localisés en Europe Centrale?

- Introduite en Occident, cette figure n'est plus un mythe explicatif de la réalité mais devient un motif ou une fantaisie. Pourquoi ?

- Enfin, pourquoi le vampire s'est-il popularisé dans les arts? Il a été codifié par les Romantiques et est présent dans les créations romantiques: 1820-1850, fin du XIX ${ }^{e}$ siècle, 1975-1995.

2 L'étude comprend les parties suivantes:

- Comment s'est construit le phénomène vampire.

- Le vampire en tant que motif.

- Relations avec occultisme, psychanalyse et médecine.

\section{Comment s'est construit le phénomène vampire}

Le mot dérive du serbe et probablement du turc.

4 Le vampire est un mort actif se nourrissant du sang de ses victimes pour garder une vigueur éternelle. Sous ce nom, des textes désignent aussi le Démon prélevant le sang des vivants et l'utilisant pour conserver en état non décomposé des corps morts, la victime meurt et devient Vampire, le concept est typique de l'Europe Centrale aux XVI ${ }^{\mathrm{e}}$ et XVII ${ }^{e}$ siècles. Au XVIII ${ }^{e}$, on s'interroge en Occident sur l'apparition de ces créatures dans le cadre judéo-chrétien.

5 Florent Montaclair conçoit le vampire comme métaphorisation de l'invasion turque ottomane et de l'histoire des peuples ouraliens et hunniques. 


\section{Vampire et invasion turque}

Les zones d'apparition des récits vampiriques sont celles de la progression de l'invasion après la prise de Constantinople (1453) : Bulgarie, Serbie, Hongrie, Pologne. Le vampire sévit en milieu chrétien, rural, surtout contre les « résistants » à l'occupation (soldats appelés heiduques).

Il s'attaque aux familles et contamine ses victimes qui deviennent vampires à leur tour. La destruction du vampire fait appel à l'autorité chrétienne (représentant de l'empereur, prêtre ou pope).

Il y a parallélisme avec l'action turque : destruction des structures familiales rurales chrétiennes, passage du droit du sang (idée de nation liée à la filiation) au droit du sol, la métaphore étant la consommation du sang par le vampire.

\section{Le vampire : métaphorisation de l'histoire des peuples de la région}

9 L'invasion ottomane est une nouvelle arrivée de peuples orientaux. Déjà, les Bulgares, les Hongrois (en partie) étaient d'origine hunnique, créant ensuite des États chrétiens. L'invasion est un contact avec cette origine que l'on avait oubliée.

10 Le vampire s'attaque à ses proches, et, de même, l'attaque ottomane est, en quelque sorte, fratricide. C'est un mythe qui, pour les Européens du Centre, explique le mouvement des populations. En Occident, il devient une figure de l'imaginaire ou motif.

\section{Un motif appelé vampire}

\section{Caractères frappant l'imaginaire collectif}

11 En Occident, à la période où les récits vampires naissent en Europe Centrale, sévit la chasse aux sorcières qui, forces du mal, prouvent l'existence du surnaturel. Au XVIII ${ }^{\mathrm{e}}$ siècle, la sorcellerie devient un motif car on ne croit plus guère au Malin. Le motif vampire est plus attrayant et n'a pas le caractère désagréable de la sorcière, dû au souvenir encore cuisant de l'Inquisition. Le succès du motif vampire est lié à cette nouveauté et à son appel aux structures imaginaires collectives connotant les aspects suivants :

- La notion de sang, synonyme de vie et de mort; de plus, certaines doctrines matérialistes attribuent à cette époque l'immortalité au sang.

- La relation du vampire avec la famille conçue comme noyau fondamental qu'il attaque.

- La relation avec la mort : le vampire est un faux immortel contredisant la notion chrétienne d'immortalité, un revenant non agréé, hors norme (à l'inverse des ressuscités par Dieu qui, tel Lazare, vivent une vie normale avant une mort normale).

En Europe Centrale, le vampire était le Mal, mais à l'ouest, il devient un objet de l'imaginaire dont on s'amuse. 


\section{Création d'un motif de la littérature fantastique}

13 La littérature fantastique se fait jour à la fois sous l'influence d'immigrés de la Révolution ayant eu contact avec des littératures étrangères et par les Romantiques qui recherchent une arme contre le Classicisme. Il s'agit pour ces derniers d'inventer un genre où règne l'imagination sans borne. Ils y placent les textes fondateurs de l'Occident et des auteurs étrangers (tels Hoffmann ou Walter Scott). Ils n'hésitent pas à modifier les textes ou les productions étrangères. Certains prennent le vampire comme sujet.

Florent Montaclair nous cite une bibliographie romantique relative au vampire :

- Origine : le vampire d'après Polidori (début du XIX siècle). C'est un vampire : il boit du sang et tue pour cela; il ne peut faire le bien mais ses autres caractères sont ceux du héros romantique : il est noble, il se situe (comme Hernani) entre " ombre et lumière ", glace et attire, il est maudit.

- Le vampire de Charles Nodier (1820), Le vampire de Scribe (1820) et Le vampire de Dumas (1851), trois pièces de théâtre dont Florent Montaclair nous donne le texte intégral en fin de volume, n'apportent rien à la figure du vampire mais prouvent la popularité du thème. Il y a des constantes communes mais, par exemple chez Dumas, apparaissent des êtres mystiques autres que le vampire. Chez Scribe, la finalité est ludique: faux vampire jouant sur les superstitions locales pour éviter un mariage forcé, parodie de texte romantique. Et puis, une pièce a des exigences qu'un simple récit n'a pas (dialogues, confidents, et aussi musique).

- La morte amoureuse de Théophile Gautier est le premier texte français non théâtral sur le thème. Un vampire femme y séduit un prêtre. Le récit offre un savant jeu sur les couleurs, en liaison avec le sang, jeu que Montaclair rapproche de textes tels que Blanche Neige (la morte aux couleurs fraîches).

- Lokis de Prosper Mérimée est un texte vampirique sans vampire : le héros mange sa femme mais n'est pas d'origine vampirique.

- Jules Verne, dans Le château des Carpathes, se livre au goût du jeu et du mélange : dans la contrée, on croit aux vampires, mais les manifestations observées sont dues à une machine.

\section{Les derniers Romantiques}

- Dracula de Bram Stocker, dernier chef d'œuvre fantastique du XIX ${ }^{\mathrm{e}}$ siècle, reprend le caractère du vampire tel que le Romantisme l'a codifié. On trouve des références à Verne, Poe, Shakespeare.

- Le cinéma américain a un aspect romantique : personnages révoltés, décalés, combatifs (par exemple dans Le silence des agneaux ou Une nuit en enfer).

- Louis, le héros de Entretien avec un vampire, roman de Anne Rice, a été vampirisé par Lestat qui est d'un type purement romantique au sens cité plus haut.

En conclusion, le personnage du vampire va de pair avec le Romantisme et le goût du jeu.

\section{Astrologie, psychanalyse, médecine}

Florent Montaclair nous donne un aperçu d'analyses du phénomène vampire dans diverses disciplines :

- Dans les ouvrages d'occultisme : assimilation-différentiation entre vampire et autres êtres mythiques (sorcier sortant du tombeau, loup-garou...). 
- On peut aussi considérer le vampire comme créature fantasmatique due à l'inconscient (approche psychanalytique) : aspect érotique (Dracula a des femmes vampires), désir de mariage mais sexualité non réussie.

- En médecine, on a interprété le vampire comme un malade que la superstition a rendu immortel : allusion à la rageur pour la morsure, la pâleur, les déformations, la pilosité.

\section{Conclusion}

17 Tel quel, l'ouvrage propose avec beaucoup de passion et d'érudition, l'historique du vampire, proposant des explications inédites à ce phénomène dit culturel qui s'est diffusé à travers l'espace et le temps. Les textes rares qui complètent l'étude autorisent un accès direct à des textes fondateurs de la sensibilité vampirique.

18 Un double regret, cependant : il manque une bibliographie récapitulative et un index des noms propres et des textes cités. On attend maintenant une étude littéraire des œuvres rééditées. 